\title{
Epiglottic retroversion in nine dogs
}

\author{
Epiglottisretroversie bij negen honden
}

\author{
K. Van Ginneken, B. Van Goethem, N. Devriendt, T. Bosmans, H. de Rooster
}

Vakgroep Kleine huisdieren, Faculteit Diergeneeskunde, Universiteit Gent, Salisburylaan 133, B-9820 Merelbeke, België

katrijn_van_ginneken@hotmail.com

\begin{abstract}
$\Lambda_{\text {bstract }}$
Epiglottic retroversion (ER) is an uncommon and poorly understood disorder of the upper respiratory tract in small breed dogs. In this retrospective study, perioperative characteristics, surgical technique, outcome, and complications in nine dogs that underwent surgical treatment for ER and/or concurrent upper respiratory tract disorders, were evaluated. The most frequently reported clinical symptoms were chronic intermittent inspiratory stridor $(89 \%)$, exercise intolerance $(\mathbf{7 8 \%})$, and dyspnea $(67 \%)$. Concurrent respiratory disorders were highly prevalent $(\mathbf{7 8 \%})$. Five dogs initially underwent a temporary epiglottopexy and two a permanent epiglottopexy. In two dogs, both suffering from concurrent laryngeal paralysis, only a unilateral cricoarytenoid lateralization was performed. After initial clinical improvement, temporary and permanent epiglottopexy eventually failed in $4 / 6$ dogs $(67 \%)$ that were available for follow-up, necessitating partial epiglottectomy as revision surgery. This resulted in a successful long-term outcome in 5/6 of these dogs $(83 \%)$. In the dogs with primary ER or in cases where the presence of secondary ER led to significant respiratory symptoms, partial epiglottectomy as a primary surgical technique appeared to be a more permanent treatment option than epiglottopexy. Both dogs with surgically corrected concurrent laryngeal paralysis without epiglottopexy or epiglottectomy showed clinical improvement. This might indicate that, in case of secondary ER, positive results can be achieved after management of the underlying respiratory disorder.
\end{abstract}

\section{SAMENVATTING}

Epiglottisretroversie (ER) is een weinig voorkomende aandoening van de bovenste luchtwegen bij kleine hondenrassen waarover nog weinig bekend is. In deze retrospectieve studie werden de perioperatieve kenmerken, de chirurgische techniek, de resultaten en de complicaties bij negen honden, behandeld voor epiglottisretroversie en/of gelijktijdig voorkomende respiratoire aandoeningen, geëvalueerd. De meest voorkomende symptomen waren chronisch intermitterende inspiratoire stridor (89\%), inspanningsintolerantie (78\%) en dyspneu (67\%). Respiratoire comorbiditeiten waren veelvoorkomend (78\%). Bij vijf honden werd een tijdelijke epiglottopexie uitgevoerd en bij twee honden een permanente. Bij twee honden, beide met larynxparalyse, werd enkel een unilaterale crico-arytenoid lateralisatie uitgevoerd. Na initiële klinische verbetering bleek de tijdelijke of permanente epiglottopexie bij 4/6 honden (67\%) gefaald te zijn tijdens de follow-up. Daarop werd een partiële epiglottectomie uitgevoerd. Dit resulteerde in een klinische verbetering bij 5/6 honden (83\%). Bij een primaire ER of wanneer de aanwezigheid van secundaire ER leidde tot significante ademhalingssymptomen, leek het uitvoeren van een partiële epiglottectomie als primaire chirurgische techniek daarom de meest succesvolle optie. Beide honden met chirurgisch gecorrigeerde larynxparalyse, die geen epiglottopexie of partiële epiglottectomie ondergingen, vertoonden een klinische verbetering. In het geval van secundaire ER kan er mogelijk ook een goed resultaat worden bereikt na behandeling van enkel de onderliggende respiratoire aandoening. 


\section{INTRODUCTION}

Epiglottic retroversion (ER) is a rare disorder in dogs characterized by retroflexion of the epiglottis towards the rima glottidis during inspiration (Mullins et al., 2014). This leads to an intermittent obstruction of the upper respiratory tract resulting in inspiratory stridor and dyspnea (Skerret et al., 2015). Similar conditions can be found in horses and humans (Woo, 1992; Parente et al., 1998; Lane et al., 2010; Terrón-Canedo and Franklin, 2013). The etiology of ER in dogs is still unknown (Skerret et al., 2015). In previous studies, it has been hypothesized that potential etiologies could be disorders of the epiglottic cartilage (Flanders and Thompson, 2009), hyoepiglotticus muscle (Amis et al., 1996a; Amis et al., 1996b; Flanders and Thompson, 2009), hypoglossal nerves (Holcombe et al., 1997), or hypothyroidism-associated peripheral neuropathy (Panciera, 2001; Cuddon, 2002; Flanders and Thompson, 2009). ER could also be secondary to, or even a component of, other concurrent upper airway disorders, which cause increased turbulence, upper airway resistance, and negative upper airway pressures (Skerret et al., 2015).

In previous studies, surgical management of ER by performing a temporary or permanent epiglottopexy has been described (Skerret et al., 2015). However, the occurrence of epiglottopexy failure was high with $37 \%$ of temporary and $62 \%$ of permanent epiglottopexies failing (Skerret et al., 2015). Partial epiglottectomy has been performed as a revision technique in two previous cases and has shown promising results (Mullins et al., 2014; Skerret et al., 2015).

The aim of this retrospective study was to evaluate the signalment, the clinical signs and comorbidities, the laryngoscopic findings, the surgical techniques performed, and the outcome in dogs diagnosed with ER. Based on the current literature regarding ER, the authors hypothesize that respiratory tract disorders and neurological comorbidities are highly prevalent in dogs with ER and that the complication rate and results during follow-up depend on the type of surgical intervention and the presence of comorbidities.

\section{MATERIALS AND METHODS}

Dogs diagnosed with ER at the Small Animal Teaching Hospital of the Faculty of Veterinary Medicine, Ghent University between 2017 and 2019 were included in this study. ER was diagnosed during (video-)laryngoscopy after physical examination. The diagnosis of ER was confirmed when the epiglottis was not positioned against the base of the tongue at inspiration. The dogs in this study were classified as low or high grade based on the laryngoscopic assessment of the severity of the obstruction of the rima glottidis and the presence of structural abnormalities of the epiglottis, by different surgeons. In low-grade patients, the epiglottis was elevated from the tongue base throughout the respi- ratory cycle, without showing any ventral movement during inspiration, resulting in a partial obstruction of the rima glottidis. In high-grade patients, the epiglottis retroflexed caudally on inspiration, resulting in complete obstruction of the rima glottidis; in some cases, its tip was even pulled into the rima glottidis.

Additionally, findings on complete blood analysis, thoracic radiographs, tracheoscopy, bronchoscopy, and/ or electrophysiological examination were reviewed retrospectively.

All of the dogs underwent at least one surgical procedure, either to correct ER and the (potential) accompanying comorbidities, or to correct the assumed underlying respiratory disorder. The initial surgical techniques used to treat ER were either a temporary or a permanent epiglottopexy. The technique for temporary epiglottopexy consisted of placing one or two mattress sutures using polypropylene (Prolene, Ethicon; range, $5 / 0$ to $2 / 0$ ) between the epiglottis, engaging the epiglottic cartilage, and the glossopharyngeal mucosa at the base of the tongue, as previously described by Flanders and Thompson (2009). To perform a permanent epiglottopexy, a wedge of mucosa ventrorostrally on the epiglottis and another caudally at the base of the tongue were excised. The edges of the wound bed between the glossopharyngeal mucosa and the epiglottis were apposed with a continuous suture line, also engaging the epiglottic cartilage, with $5 / 0$ poliglecaprone (Monocryl, Ethicon) or $3 / 0$ polyamid (Ethilon, Ethicon), after which the position of the epiglottis was assessed with the tongue in a neutral position (Flanders and Thompson, 2009). In case of failure of these techniques, a partial epiglottectomy was performed by excising one third to two thirds of the distal epiglottis, followed by an evaluation of the patency of the larynx (Mullins et al., 2014). A cruciate suture was placed to prevent retraction of the mucosae.

The anesthetic and analgesic protocols used were based on the preference of the attending anesthesiologist. All dogs were intubated and anesthesia was maintained using gas anesthesia.

Improvement at follow-up was defined as excellent, good, or moderate based on the decrease in number and severity of the respiratory signs. In case of epiglottopexy failure or no improvement of the symptoms, the outcome was described as bad. Telephone interviews were conducted to provide an extra indication of long-term results. The owners were additionally asked to compare the severity of the respiratory signs prior to treatment (improved, similar, or worse). The owners were also asked if they had noticed any evolution of the disease after treatment (stable, improved, worsened) and if they were satisfied with the result (yes, no).

\section{RESULTS}

\section{Patient population}

Nine dogs with ER were identified in the hospital's 

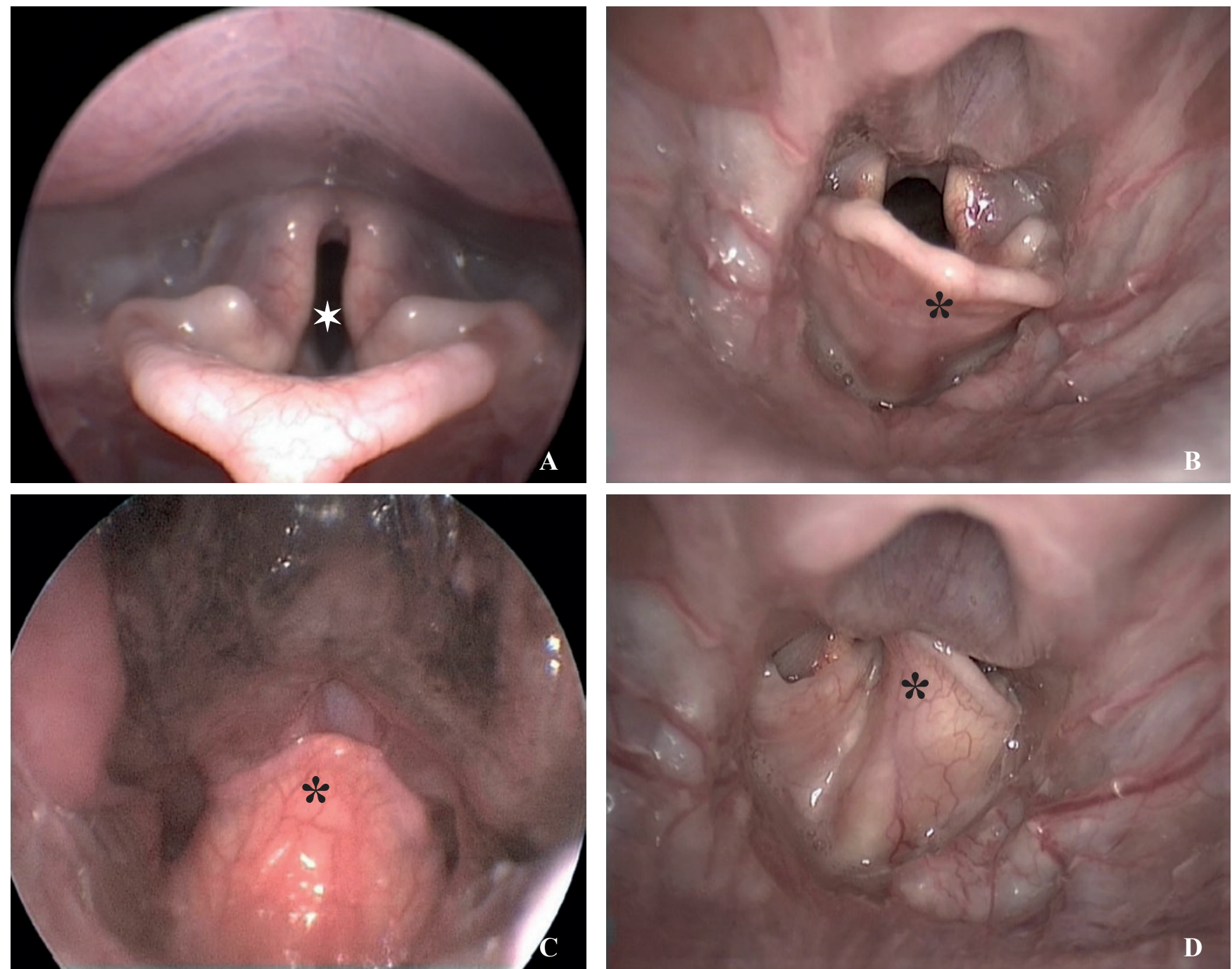

Figure 1. Endoscopic images of the larynx during inspiration. A. Normal larynx with epiglottis (asterisk) positioned against the tongue base, B. low-grade epiglottic reversion (ER) with the epiglottis elevated from the tongue base, C. high-grade ER with the epiglottis closing off the rima glottidis (star), D. high-grade ER with the epiglottis collapsing into the rima glottidis.

patient records during the study's period. Represented breeds were Maltese $(\mathrm{n}=2)$, Chihuahua $(\mathrm{n}=2)$, Cavalier King Charles spaniel $(\mathrm{n}=2)$, Shih tzu $(\mathrm{n}=1)$, Yorkshire terrier $(\mathrm{n}=1)$, and Pomeranian $(\mathrm{n}=1)$. The median age was 8.1 years (range, 1.2 to 9.5 years). Five dogs $(56 \%)$ were more than seven years old at the time of diagnosis, two dogs $(22 \%)$ were between three and seven years of age, and two dogs $(22 \%)$ were less than three years old. Sex distribution was $6 / 9$ male $(67 \%)$, of which $4 / 6$ were neutered $(67 \%)$, and $3 / 9$ were female dogs $(33 \%)$, all spayed. The median weight was $4.6 \mathrm{~kg}$ (range, 2.9 to $13.5 \mathrm{~kg}$ ). The median body condition score was 5/9 (range, 4/9 to 7/9).

\section{Clinical presentation}

Eight patients $(89 \%)$ came in through consultations, whereas one patient $(11 \%)$ was presented at the emergency services. The presenting respiratory clinical signs were inspiratory stridor $(89 \%)$, exercise intolerance (78\%), dyspnea (67\%), coughing and gag- ging (44\%), reverse sneezing (44\%), cyanosis $(44 \%)$, tachypnea (33\%), sneezing (22\%), and nasal stridor $(22 \%)$. Six out of the nine dogs $(67 \%)$ showed intermittent respiratory signs, mainly provoked by excitation or exercise, whereas three dogs $(33 \%)$ continuously had symptoms. The median time since the start of the symptoms at presentation was twelve months (range, 1 week to 8.6 years).

\section{Diagnostic work-up}

All patients underwent laryngoscopic examination (Figure 1). Thirty-three percent of the dogs were considered low grade (3/9). In one of these dogs, the epiglottis was bent caudally with a concave lingual side. Sixty-seven percent were considered high grade (6/9). In one of these dogs, the epiglottis was partially pulled into the rima glottidis during inspiration.

Seven out of the nine patients (78\%) had concurrent upper airway disorders (Table 1). On laryngeal inspection, 5/9 dogs $(56 \%)$ had brachycephalic obstructive 

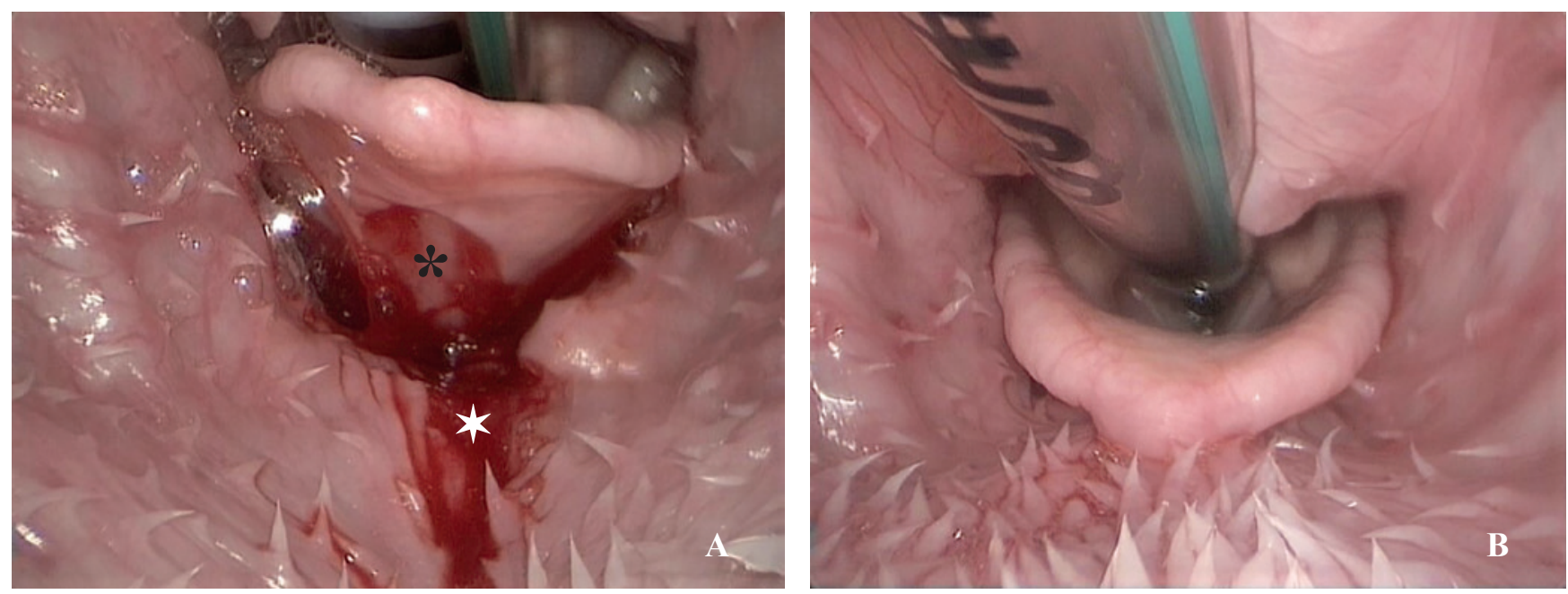

Figure 2. Intra-operative images of a permanent epiglottopexy. A. A wedge of mucosa ventrorostrally on the epiglottis (asterisk) and caudally at the base of the tongue (star) is excised. B. Following fixation by placement of a continuous suture line to the wound bed between the glossopharyngeal and epiglottic mucosae, the position of the epiglottis is assessed with the tongue in a neutral position; the rima glottidis is now patent throughout the respiratory cycle.

airway syndrome (BOAS) and 3/9 dogs (33\%) had laryngeal paralysis. The five dogs presented with BOAS had hyperplastic and/or elongated soft palate (4/5), hyperplastic and/or everted tonsils (4/5), laryngeal collapse grade I (1/5), and relative macroglossia $(1 / 5)$.

Six out of the nine dogs $(67 \%)$ underwent tracheoscopy of which $2 / 6$ were diagnosed with grade III tracheal collapse, 1/6 with grade I tracheal collapse, 1/6 showed an increased presence of mucus, and $2 / 6$ had no abnormalities. All dogs diagnosed with BOAS had high-grade ER, so did 2/3 dogs with laryngeal paralysis. One of the dogs with grade III tracheal collapse had high-grade ER.

In eight out of the nine dogs (89\%) thoracic radio- graphs were taken prior to surgery. In seven of these patients, no abnormalities of the respiratory tract were detected. In only $1 / 3$ patients diagnosed with tracheal collapse, there were radiological indications present for this disorder. One patient with ER and concurrent laryngeal paralysis underwent electromyographic and electroneurographic examination to screen for potential underlying polyneuropathy, but for both examinations, the results were negative.

\section{Surgical treatment}

Temporary epiglottopexy was performed in 5/9 dogs $(56 \%)$. In one of these five patients also pala-

Table 1. Long-term results (obtained by telephone interview) and epiglottopexy failure in function of the surgical technique performed and the presence of concurrent respiratory tract disorders.

\begin{tabular}{|c|c|c|c|c|c|c|c|c|c|}
\hline $\mathbf{N}^{\circ}$ & Breed & $\begin{array}{l}\text { ER } \\
\text { grade }\end{array}$ & BOAS & LP & TC & $\begin{array}{l}\text { Surgical } \\
\text { technique }\end{array}$ & Recurrence & $\begin{array}{l}\text { Revision } \\
\text { partial } \\
\text { epiglottectomy }\end{array}$ & $\begin{array}{l}\text { Long-term } \\
\text { result }\end{array}$ \\
\hline 1 & Pomeranian & Low & & & & Temporary EP & Yes & Yes & Moderate \\
\hline 2 & Maltese & High & Yes & Yes & Yes & $\begin{array}{l}\text { Temporary EP } \\
+ \text { CAL }\end{array}$ & Yes & No & $\mathrm{Bad}$ \\
\hline 3 & Chihuahua & Low & & & Yes & Temporary EP & & & Moderate \\
\hline 4 & Yorkshire terrier & High & Yes & & & Temporary EP & Yes & Yes & Good \\
\hline 5 & CKCS & High & Yes & & & $\begin{array}{l}\text { Temporary EP } \\
+ \text { palatoplasty } \\
+ \text { tonsillectomy }\end{array}$ & & & Excellent \\
\hline 6 & Shih Tzu & High & & & & Permanent EP & Yes & Yes & Excellent \\
\hline 7 & CKCS & High & Yes & Yes & & CAL & & & Excellent \\
\hline 8 & Chihuahua & High & Yes & & & $\begin{array}{l}\text { Permanent EP } \\
\text { + palatoplasty }\end{array}$ & Patient lost to & llow-up & \\
\hline 9 & Maltese & Low & & Yes & Yes & CAL & & & Good \\
\hline
\end{tabular}

CKCS: Cavalier King Charles spaniel, BOAS: brachycephalic obstructive airway syndrome, LP: laryngeal paralysis, TC: tracheal collapse, EP: epiglottopexy, CAL: unilateral cricoarytenoid lateralisation. 
toplasty and unilateral tonsillectomy were performed to treat the concurrent BOAS. One other patient $(1 / 5)$ additionally underwent cricoarytenoid lateralization for concurrent laryngeal paralysis.

Permanent epiglottopexy was performed in 2/9 dogs $(22 \%)$ (Figure 2). One of these two patients also underwent concomitant palatoplasty.

All three patients diagnosed with laryngeal paralysis underwent unilateral cricoarytenoid lateralization. For two of these patients $(67 \%)$, this was the only surgical procedure that was performed. In the remaining patient, temporary epiglottopexy was also performed. The three patients with concurrent tracheal collapse were surgically treated for ER by performing temporary epiglottopexy $(n=2)$, and/or concurrent laryngeal paralysis $(n=2)$.

\section{Short-term evaluation}

Six out of the seven patients that underwent epiglottopexy (five temporary and one permanent) were presented for a control visit one month post-operatively. One patient was lost to follow-up. Clinical improvement was seen in $4 / 6$ of these dogs $(67 \%$, four temporary and zero permanent), of which one dog that received temporary epiglottopexy, did not show clinical signs anymore. Complications after epiglottopexy occurred in $2 / 6$ dogs $(33 \%$, both after temporary epiglottopexy) and consisted of dysphagia, which only lasted for two weeks in one of the dogs. However, none of the patients developed symptoms of aspiration pneumonia. The two patients that only underwent laryngeal paralysis treatment showed major clinical improvement.

\section{Long-term evaluation}

Eight patients were available for long-term followup. The median long-term follow-up was 16 months (range, 5 to 23 months). Only one patient, that underwent temporary epiglottopexy, was presented at the control visit one year post-operatively. Telephone interviews were available for 8/9 dogs (89\%).

One patient that received permanent epiglottopexy, was lost to follow-up. Four out of the six remaining patients $(67 \%)$ that received epiglottopexy (three temporary, one permanent) showed recurrence of their respiratory symptoms after a period of initial improvement, suggesting failure of the epiglottopexy. The median interval between epiglottopexy and failure of this technique was 1.5 months (range, 1 to 12 months). In three dogs, recurrence of the clinical signs was reported at the time of the control visits (one temporary and one permanent one month postoperatively; one temporary one year post-operatively) and for one, it was the reason for early revisit at 1.5 months post-operatively. Two of these four dogs did not have any comorbidities. One out of two dogs with low-grade ER (50\%) and 3/4 dogs with high-grade
ER (75\%) experienced epiglottopexy failure. Failure of the epiglottopexy was diagnosed with a laryngeal inspection in all four dogs. In 3/4 dogs, partial epiglottectomy was performed as a revision surgery. The other dog initially showed clinical improvement after temporary epiglottopexy and cricoarytenoid lateralization. However, the one-year-post-operative control visit revealed an increase in severity of the respiratory symptoms due to epiglottopexy failure, the limited effect of cricoarytenoid lateralization, and grade III tracheal collapse. No revision surgery was performed in this patient. All dogs that underwent partial epiglottectomy during revision surgery showed clinical improvement. One dog even obtained excellent results and had resolution of all clinical signs. However, two dogs showed dysphagia since the partial epiglottectomy (2/3 dogs or $67 \%)$. None of these patients developed clinical signs of aspiration pneumonia within the follow-up period.

Improvement of respiratory signs was present in $5 / 6$ dogs $(83 \%)$ that underwent temporary or permanent epiglottopexy, or epiglottectomy. One of these dogs only underwent temporary epiglottopexy and palatoplasty for concurrent BOAS, and obtained excellent results remaining free of clinical signs.

Of both dogs that only had their concurrent laryngeal paralysis treated, one clinically improved and one obtained excellent results and remained free of clinical signs. Regarding the patients with concurrent tracheal collapse, the patient with grade I tracheal collapse showed long-term clinical improvement after temporary epiglottopexy. The two patients with medically-treated grade III tracheal collapse were clinically stable.

Eight out of the nine owners participated in the follow-up by telephone survey. The owners hereby described the severity of the respiratory symptoms in comparison to the pre-operative clinical signs as 'improved' in six cases $(75 \%)$, as 'similar' in one case $(12.5 \%)$ and as 'worse' in another case $(12.5 \%)$. The post-operative clinical evolution of the respiratory symptoms was described as 'stable' (75\%), 'improving' $(12.5 \%)$ and 'worsening' $(12.5 \%)$. Seven out of the eight owners $(88 \%)$ were satisfied with the treatment of their dog. .

\section{DISCUSSION}

Surgical treatment of ER or its underlying respiratory pathology resulted in clinical improvement and high overall owner satisfaction.

More than two thirds of the patients in this study had concurrent respiratory disorders, including BOAS, laryngeal paralysis, or tracheal collapse, at the time of the diagnosis of ER. This complies with the results of Skerret et al. (2015). It is therefore difficult to ascertain the true importance of ER as a primary condition and its ability to cause respiratory discom- 
fort on itself. When ER occurs as a secondary disease due to increased inspiratory airway resistance from an underlying primary respiratory disorder, correction of this primary disorder might give clinical improvement of the respiratory issues. In this study, this was demonstrated in two dogs with ER in combination with laryngeal paralysis. Despite limiting surgical treatment to the correction of laryngeal paralysis, major improvement of the clinical signs occurred. In case of ER as a primary pathology, resulting in secondary changes to the upper respiratory tract, surgical correction of ER itself is advised. Only in two dogs, ER was identified as the primary cause of the respiratory symptoms. In most other dogs, the relation between the different diseases was more difficult to unravel, leading to a combination of treatment procedures. This has also been supported by the findings of Skerret et al. (2015), who reported a higher percentage of dogs that showed improvement of respiratory symptoms after combined treatment of concurrent respiratory tract disorders than of dogs that only underwent surgical treatment for ER.

Although ER can easily be diagnosed via direct laryngoscopy, laryngeal inspection is not always conclusive when the ER only occurs when induced by exercise or excitation (Mullins et al., 2014). Also, any pressure at the level of the epiglottis or rostral lingual traction may result in false negative results (Skerret et al., 2015). Lastly, ER is a relatively rare and recently discovered condition and therefore not widely recognized in veterinary medicine. Therefore, ER might be underdiagnosed and possibly undertreated.

Skerret et al. (2015) described temporary or permanent epiglottopexy for surgical treatment of ER. In the present study, however, almost half of the epiglottopexies failed within two months after the surgery. In the study by Skerret et al. (2015), 37\% of the temporary and $62 \%$ of the permanent epiglottopexies failed, suggesting that the additional trauma caused by excision of mucosa to obtain a permanent epiglottopexy is unnecessary (Skerret et al., 2015). In the present study, this suggestion could not be enforced due to the small patient population. The epiglottopexy procedures failed in 2/4 patients with concurrent respiratory disorders and both patients without concurrent respiratory disorders. This finding is somehow surprising since, due to the presence of increased negative upper respiratory pressures, a higher prevalence of epiglottopexy failure was expected in patients with concurrent respiratory tract disorders. Furthermore, the grade of ER seemed to affect epiglottopexy failure rates with high-grade dogs showing a higher failure percentage.

Dogs, in which the epiglottopexy seemed to have failed, underwent partial epiglottectomy, which resulted in an overall $83 \%$ long-term successful outcome. Removal of the distal tip of the epiglottis avoids complete rima glottidis obstruction when the epiglottis aberrantly retracts on inspiration (Mullins et al., 2014). The potential disadvantage, however, is that fluid or food particles may enter the trachea during swallowing. On the other hand, the importance of the presence of the epiglottis during swallowing is controversial (Medda et al., 2003). In this study, dysphagia was seen in 4/7 dogs, with a higher prevalence after partial epiglottectomy than after epiglottopexy. In one dog, this was only a temporary complication, whereas in the other three dogs, this complication persisted as a mild hindrance. None of these dogs developed aspiration pneumonia within the follow-up period. Further studies are needed to determine the most suited amount of epiglottis to be removed for ER.

The limitations of this study include the retrospective design and small patient population. Therefore, it is impossible to draw any statistical conclusions and larger studies are needed to further define the most successful treatment option for ER. Also, the low owner compliance regarding control visits led to more subjective long-term follow-up data. Furthermore, the surgical interventions in this study were performed by different surgeons, using different suture materials and numbers of sutures. Therefore, it is hard to evaluate the factors influencing the failure rate of the epiglottopexies. Moreover, not all dogs diagnosed with BOAS underwent surgical treatment for this condition, due to owner consent and/or the deemed necessity for surgical treatment.

Since epiglottopexy failure is highly prevalent, performing a partial epiglottectomy as a primary surgical technique appears to be a more satisfying treatment option in case of primary ER or when the presence of secondary ER leads to significant respiratory symptoms. On the other hand, too little is known about the potential risk factors for dysphagia. The high prevalence of concurrent respiratory disorders might indicate that ER is secondary to, or an unrecognized component of, these disorders. Therefore, in selected dogs, satisfying results could possibly also be achieved after management of only the concurrent respiratory disorders. The prognosis after surgical treatment of ER and/or concurrent respiratory disorders is generally favorable.

\section{REFERENCES}

Amis T.C., O’Neill N., Van der Touw T., Brancatisano A. (1996a). Electromyographic activity of the hyoepiglotticus muscle in dogs. Respiration Physiology 104, 159167.

Amis T.C., O’Neill N., Brancatisano A. (1996b). Influence of hyoepiglotticus muscle contraction on canine upper airway geometry. Respiration Physiology 104, 179-185.

Cuddon P.A. (2002). Acquired canine peripheral neuropathies. Veterinary Clinics of North America: Small Animal Practice 32, 207-249.

Flanders J.A., Thompson M.S. (2009). Dyspnea caused by epiglottic retroversion in two dogs. Journal of the American Veterinary Medical Association 235, 1330-1335. 
Holcombe S.J., Derksen F.J., Stick J.A., Robinson N.E. (1997). Effects of bilateral hypoglossal and glossopharyngeal nerve blocks on epiglottic and soft palate position in exercising horses. American Journal of Veterinary Research 58, 1022-1026.

Lane J.G., Bladon B., Little D.R.M., Naylor J.R.J., Franklin S.H. (2010). Dynamic obstructions of the equine upper respiratory tract. Part 1: Observations during high-speed treadmill endoscopy of 600 Thoroughbred racehorses. Equine Veterinary Journal 38, 401-408.

Medda B.K., Kern M., Ren J., Xie P., Ulualp S.O., Lang I.M., Shaker R. (2003). Relative contribution of various airway protective mechanisms to prevention of aspiration during swallowing. American Journal of Physiology Gastrointestinal and Liver Physiology 284, 933-939.

Mullins R., McAlinden A.B., Goodfellow M. (2014). Subtotal epiglottectomy for the management of epiglottic retroversion in a dog. Journal of Small Animal Practice $55,383-385$.
Panciera D.L. (2001). Conditions associated with canine hypothyroidism. Veterinary Clinics of North America: Small Animal Practice 31, 935-950.

Parente E.J., Martin B.B., Tulleners E.P. (1998). Epiglottic retroversion as a cause of upper airway obstruction in two horses. Equine Veterinary Journal 30, 270-272.

Skerrett S., McClaran J., Fox P., Palma D. (2015). Clinical features and outcome of dogs with epiglottic retroversion with or without surgical treatment: 24 cases. Journal of Veterinary Internal Medicine 29, 1611-1618.

Terrón-Canedo N., Franklin S. (2013). Dynamic epiglottic retroversion as a cause of abnormal inspiratory noise in six adult horses. Equine Veterinary Education 25, 565569.

Woo P. (1992). Acquired laryngomalacia: epiglottis prolapse as a cause of airway obstruction. Annals of Otology, Rhinology and Laryngology 101, 314-320.

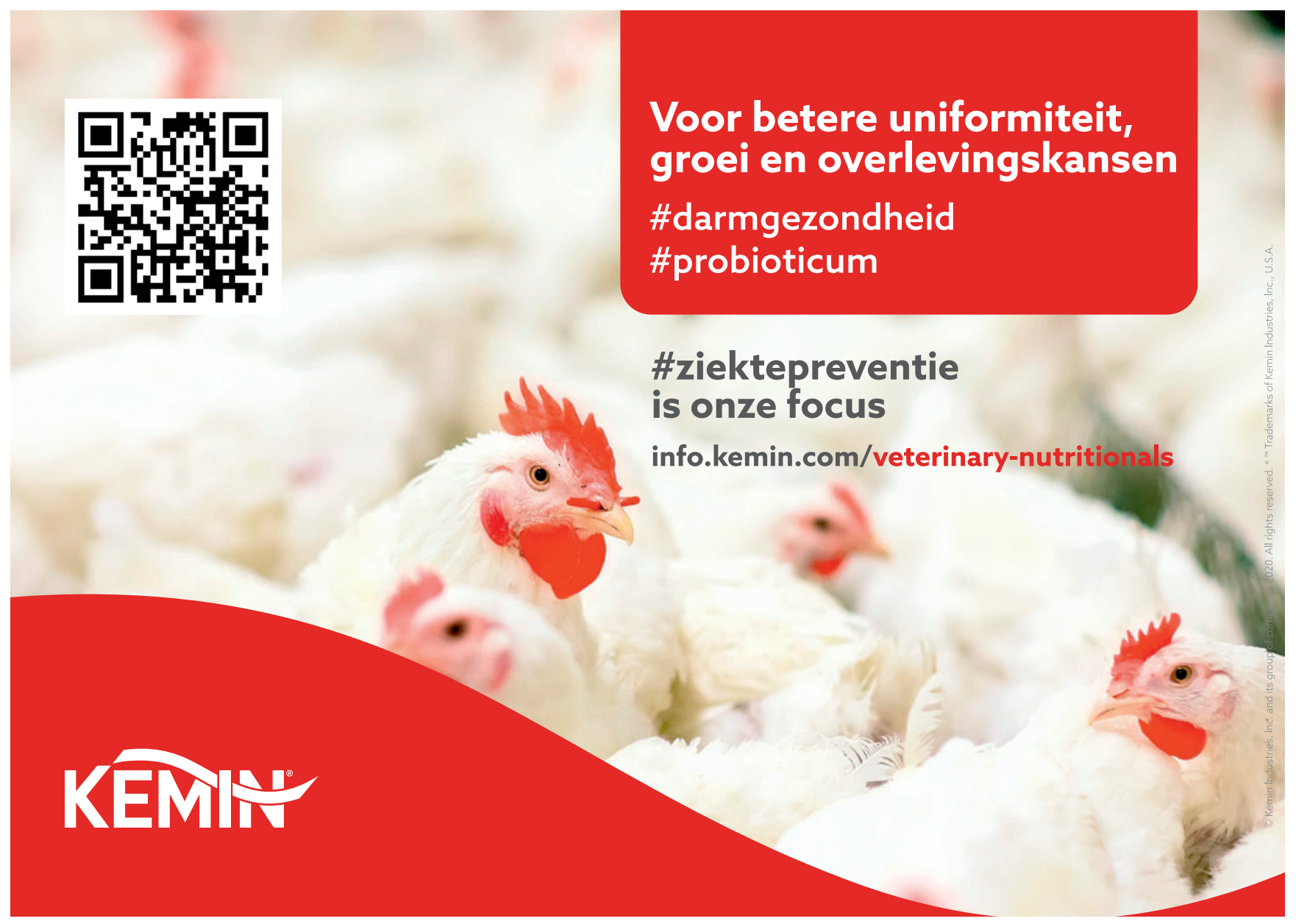

